\title{
Erratum
}

Ichthyol Res (2007) 54: 317

DOI 10.1007/s10228-007-0407-1

\section{Parasperm: morphological and functional studies on nonfertile sperm}

Youichi Hayakawa

Ichthyol Res (2007) 54: 111-130

DOI 10.1007/s10228-006-0383-X

On page 116, Figure 3 should change:

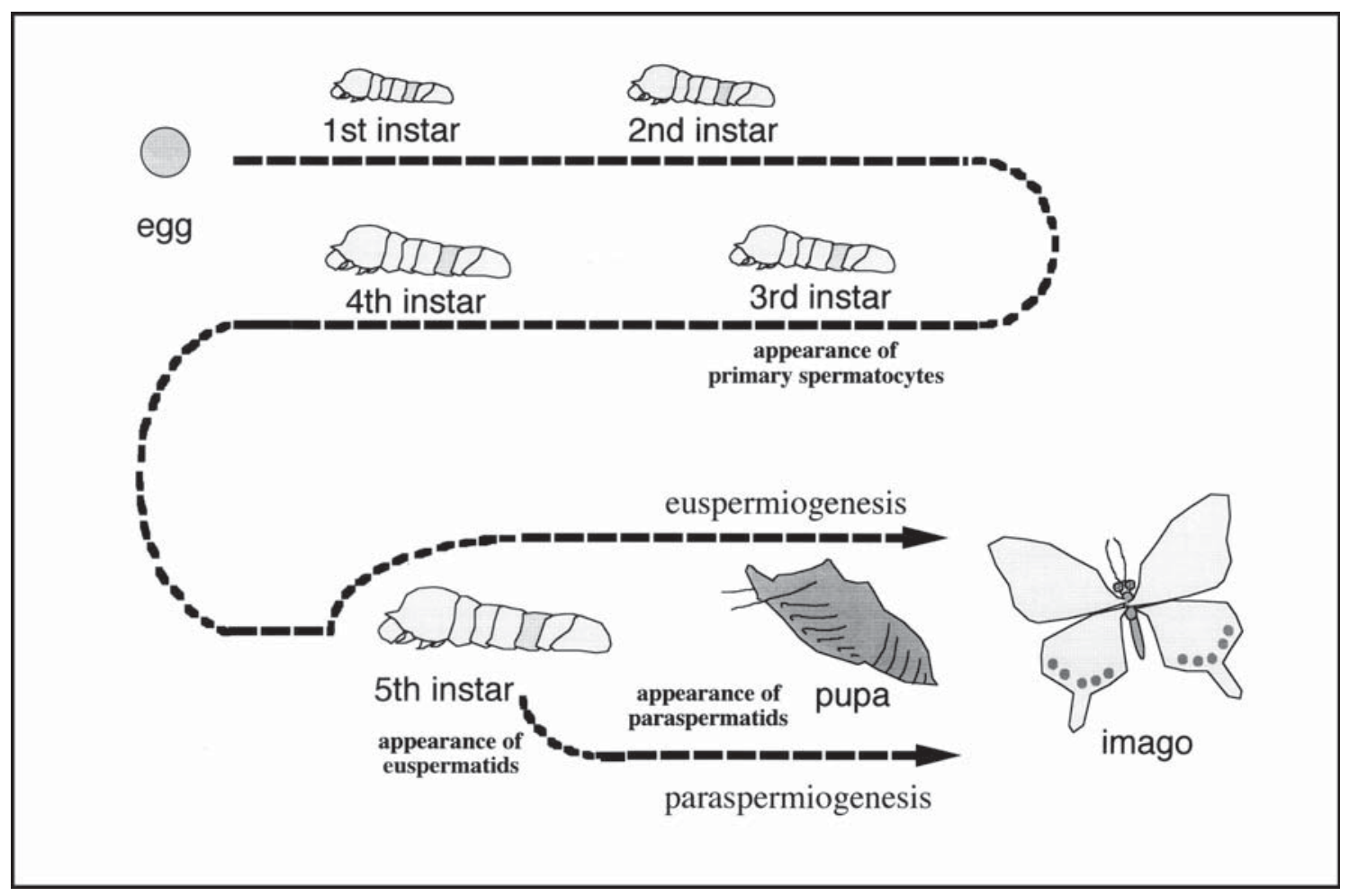

Fig. 3. Spermatogenesis in Lepidoptera. Euspermiogenesis starts at the early stage of the fifth instar, and eusperm appear at the middle of the fifth instar. Paraspermatogenesis occurs at the last phase of the fifth instar, and parasperm appear during pupation. [Figures drawn by the author, referring to Lai-Fook (1982a,b), Fridländer (1997), and Kawamura and Sahara (2002)] 